\title{
Impaired driving charges in injured impaired drivers requiring treatment in an emergency department
}

\author{
Warren Fieldus, MD*; Ed Cain, MD
}

\section{ABSTRACT}

Objective: To determine the percentage of injured impaired drivers brought to the only trauma centre in Nova Scotia who were charged with impaired driving.

Methods: This retrospective observational study identified alcohol impaired drivers involved in a motor vehicle crash (MVC) brought to the emergency department (ED). Patients were selected based on blood alcohol concentrations (BACs) found to be above the legal limit. Medical records were examined to determine if the patient was the driver in an MVC. Patient records were then cross-referenced with a police database to determine the percentage of injured impaired drivers who were charged with impaired driving.

Results: Between April 1, 2006, and April 1, 2008, 1,102 patients brought to the QEII Health Sciences Centre (QEII HSC) ED were found to have BACs over the legal limit. Of these patients, only $57(5.2 \%)$ were found to have been the driver in an MVC. The majority of patients were male (49; $86 \%$ ), with an average age of 32 years. Most injuries (51; $89.5 \%)$ were the result of a single-vehicle crash. The mean Glasgow Coma Scale score was 12.6, and the mean Injury Severity Score was 14.4. Cross-referencing with police records showed that only $22.8 \%$ (13 of 57 ) of injured drivers were charged with impaired driving. Those drivers not charged with impaired driving had a significantly lower median BAC and median age.

Conclusion: During the study, the majority of alcoholimpaired drivers injured in an MVC who were brought to the QEII HSC ED for assessment of their injuries were not charged with impaired driving.

\section{RÉSUMÉ}

Objectif: L'étude avait pour objectif de déterminer le pourcentage de conducteurs ivres, blessés, et transportés au seul centre de traumatologie de la Nouvelle-Écosse, qui ont été accusés de conduite avec facultés affaiblies.

Méthodes: L'étude d'observation rétrospective visait à repérer les conducteurs ivres, blessés dans un accident de la route (AR), et transportés au service des urgences. Les patients étaient sélectionnés si le taux d'alcoolémie (TA) dépassait la limite légale. Nous avons d'abord examiné les dossiers médicaux afin de déterminer si les patients en question conduisaient au moment de I'AR. II y a ensuite eu recoupement des dossiers des patients avec une base de données de services policiers afin d'établir le pourcentage de conducteurs ivres, blessés, qui ont été accusés de conduite avec facultés affaiblies.

Résultats: Entre le 1er avril 2006 et le 1er avril 2008, parmi les patients transportés au service des urgences du Queen Elizabeth II Health Sciences Centre (QEII HSC), 1,102 avaient un TA supérieur à la limite légale. Sur ce nombre, 57 (5.2\%) seulement conduisaient au moment de I'AR. Les patients étaient, en grande majorité, des hommes (49; $86 \%$ ), âgés en moyenne de 32 ans. La plupart du temps (51; 89.5\%), les blessures résultaient d'un accident mettant en cause un seul véhicule. Le résultat moyen sur l'échelle de Glasgow était de 12.6 et celui concernant la gravité des blessures de 14.4. Les recoupements avec les casiers judiciaires ont révélé que $22.8 \%$ (13 sur 57 ) seulement des conducteurs blessés avaient été accusés de conduite avec facultés affaiblies. Les conducteurs non accusés avaient un TA médian et un âge médian passablement moins élevés.

Conclusion: Dans la présente étude, la plupart des conducteurs ivres, blessés dans un AR, et transportés au service des urgences du QEII HSC pour l'évaluation des blessures n'ont pas été accusés de conduite avec facultés affaiblies.

Keywords: alcohol-impaired driving, emergency department, impaired driving charges

On average, impaired driving kills 1,212 persons, injures 71,500 , and costs 11.3 billion dollars each year in Canada. ${ }^{1}$ Many individuals repeatedly drive while alcohol impaired. ${ }^{2,3}$ Clearly, impaired drivers represent a significant risk to both themselves and others. There is considerable evidence supporting the effectiveness of legal sanctions in reducing impaired driving recidivism. ${ }^{4-6}$

From the *Department of Emergency Medicine, QEII Health Sciences Centre, Halifax, NS.

Correspondence to: Dr. Warren Fieldus, Department of Emergency Medicine, QEll Health Sciences Centre, HI 355, 1796 Summer Street, Halifax, NS B3H 3A7; wfieldus@dal.ca.

This article has been peer reviewed. 
Despite this, there is a growing body of literature describing the phenomenon of low prosecution rates of impaired drivers brought to the emergency department (ED) for treatment of their injuries.

The first publication of this phenomenon was a US study in 1984 of impaired drivers who were admitted to hospital for motor vehicle crash (MVC)-related injuries. ${ }^{7}$ Despite police indicating a high suspicion of alcohol involvement in the injured drivers, no impaired driving charges were laid. Several other US-based studies have since confirmed this phenomenon, with an average of only $21 \%$ of injured impaired drivers being charged with impaired driving when brought to hospital for assessment of their injuries..$^{8-11}$

Three recent studies have also reported this phenomenon in Canada. The first was an 8-year review of the British Columbia Trauma Registry. ${ }^{12}$ Identified patients were cross-referenced with a provincial insurance database that records all criminal code and motor vehicle offences. In this study group, only $11 \%$ of injured impaired drivers were convicted of impaired driving and $8.4 \%$ of another criminal offense. This was despite the fact that police listed ethanol as a contributing factor in $71 \%$ of crashes. The $\mathrm{BC}$ database only included conviction rates, so it is unknown how many people were charged but not convicted of that offense. The second study was a review of the Calgary Health Region trauma database from 1995 to 2003 involving 185 injured alcoholimpaired drivers. ${ }^{13}$ The authors found that only $41 \%$ were charged by police. Finally, another British Columbia-based study reporting recidivism rates in injured alcohol-impaired drivers found that only $6.7 \%$ were convicted with impaired driving and $7.1 \%$ of another criminal code offense. ${ }^{2}$

Many reasons have been suggested for the low proportion of charges in injured impaired drivers brought to the ED, including sympathy for the driver's injuries, difficulty obtaining blood alchohol concentrations (BACs), and poor communication between police and medical professionals. ${ }^{14,15}$ Impaired drivers continue to represent a significant threat to themselves and others. Therefore, interventions into their deadly behaviour, including legal sanctions, are necessary. Unfortunately, impaired drivers brought to the ED seem to be protected from prosecution. The goal of this study was to determine if the phenomenon of low charge rates of injured alcohol-impaired drivers also exists in eastern Canada by determining the percentage of injured impaired drivers brought to the only level 1 trauma centre in Nova Scotia who were charged with impaired driving.

\section{METHODS}

\section{Design and setting}

This was a retrospective observational study of alcohol-impaired patients, injured in an MVC, who were brought to the QEII Health Sciences Centre (QEII HSC) ED in Halifax, Nova Scotia. The QEII HSC is the only level 1 trauma centre in the province of Nova Scotia and manages an average of 60,000 patients per year. All patients 16 years and over seen in the QEII HSC ED between April 1, 2006, and April 1, 2008, were eligible for the study. Patients were included if they were found to have a BAC greater than $17.3 \mathrm{mmol} / \mathrm{L}$ and were determined to be the driver in an MVC. At the QEII HSC, there is a policy for all trauma team activations to have a BAC routinely drawn. For other nontrauma team patients, BACs are drawn at the discretion of the ED physician. Patients were excluded if they died during transport to hospital or in the ED, if they were transferred from another medical facility, or if it could not be determined whether they were the driver in an MVC. The study was approved by the Capital Health Research Ethics Board.

\section{Data collection}

Potential cases were initially identified by searching the ED's electronic database (EDIS) for any patient with a recorded $\mathrm{BAC}$ greater than $17.3 \mathrm{mmol} / \mathrm{L}$ (the legal limit in Nova Scotia). EDIS contains information on all patients admitted to the ED regardless of their final disposition or consulting or treating service. Next, the medical records, including prehospital, ED, and trauma team reports, of all potential cases were reviewed to determine which cases were drivers of a motor vehicle involved in an MVC. From these records, the following information was recorded: medical record numbers, date of incident, date of birth, age, gender, BAC, earliest Glasgow Coma Scale (GCS) score, Injury Severity Score (ISS), and if it was a single-vehicle collision. If it could not be determined whether the patient was involved in an MVC or if the patient was the driver, the case was not included. 
The final list of injured impaired drivers brought to the ED was then manually cross-referenced with a list of impaired driving charges for the entire province of Nova Scotia supplied by Halifax Regional Police. This database contained information on patients charged with impaired driving by both the Halifax Regional Police and the Royal Canadian Mounted Police. At no point in the study did the police have access to patient records. To maximize patient privacy, only the date of incident and the patient's gender, age, and date of birth were used to cross-reference whether the patient had been charged. An exact match of each of the above variables was needed; otherwise, the patient was considered not to have been charged. As a form of quality assurance, $10 \%$ of the records were crossreferenced a second time by a research paramedic blinded to the study protocol.

\section{Data analyses}

Descriptive statistics were generated, including the primary outcome (percentage of injured impaired drivers involved in an MVC and brought to the ED who are charged with impaired driving). Multivariate logistic regression was performed for impaired driving charges controlling for the following covariates: ISS, GCS score, BAC, single-vehicle crash status, age, and sex. A statistician not associated with the study performed all statistical analyses. As the data were not normally distributed, nonparametric statistical analysis was used with the Mann Whitney $U$ test for continuous data and the chi-square test for categorical data.

\section{RESULTS}

During the 2-year study period, 1,102 patients brought directly to the QEII HSC ED were found to have BACs over the legal limit. Figure 1 shows the characteristics of the study flow. Only 84 (7.62\%) of these patients were found to have been injured as the result of an MVC, with 57 of these patients further determined to be the driver. The characteristics of the study population are shown in Table 1 . Most drivers were male, with an average age of 32 years (range 1672 years). The mean GCS score was 12.6, and the

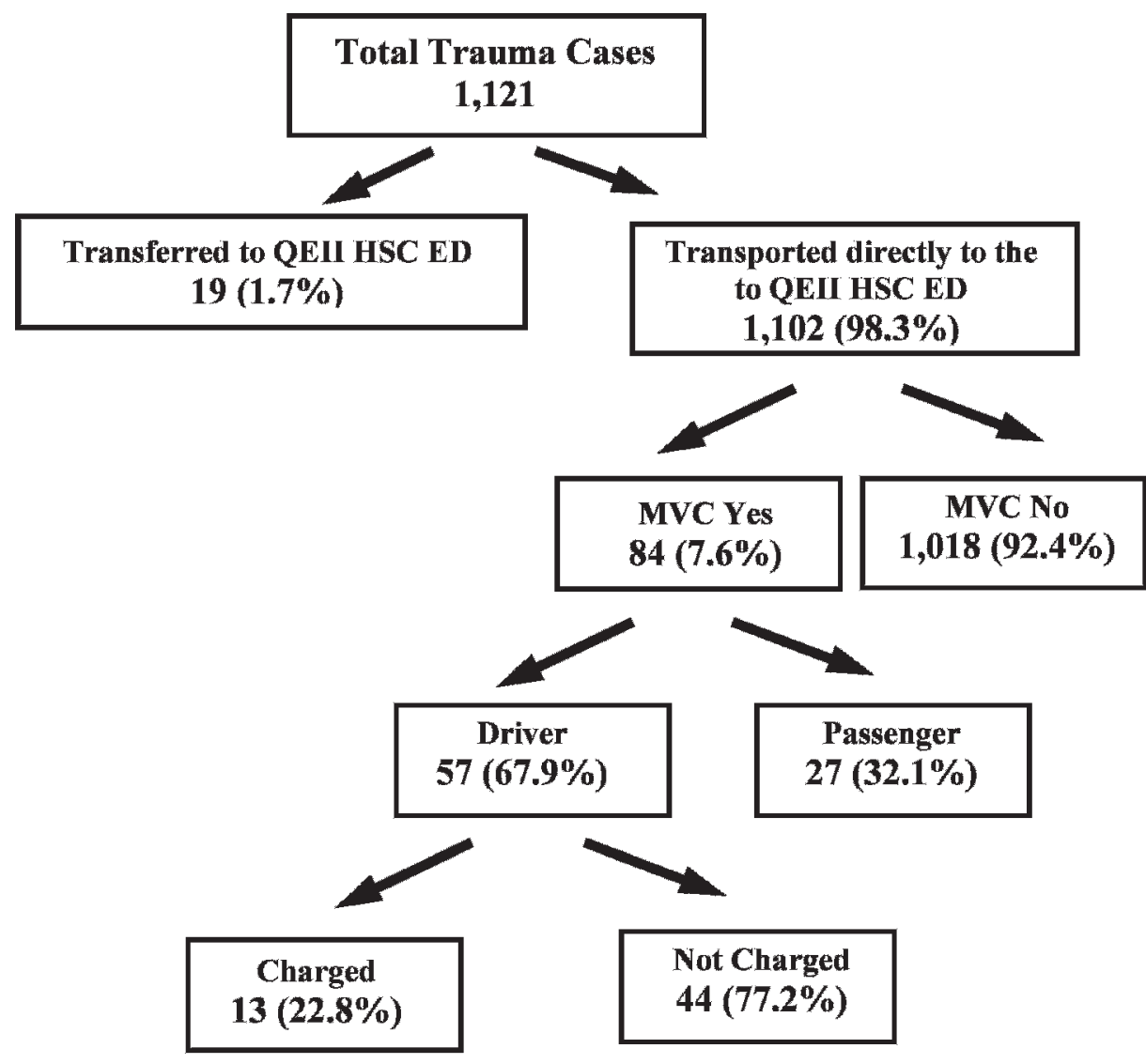

Figure 1. Flow of 1,121 patients who presented to the QEII Health Sciences Centre (QEII HSC) emergency department (ED) with trauma during a 2-year period (2006-2008). MVC = motor vehicle crash. 


\begin{tabular}{|c|c|c|}
\hline Factor & Mean (SD) & Range \\
\hline Age (yr) & $32.4(13.0)$ & $16-72$ \\
\hline Male sex, (\%) & 86 & \\
\hline $\mathrm{BAC}(\mathrm{mmol} / \mathrm{L})$ & $40.4(13.0)$ & $19-69$ \\
\hline Single-vehicle crash, (\%) & 89.5 & \\
\hline Injury Severity Score & $14.4(12)$ & $0-45$ \\
\hline Glasgow Coma Scale score & $12.6(3.8)$ & $3-15$ \\
\hline
\end{tabular}

median ISS was 14.4 (interquartile range). The majority $(51 ; 89.5 \%)$ of MVCs were single-vehicle crashes.

The mean BAC was $40.4 \pm 13.0 \mathrm{mmol} / \mathrm{L}$. Crossreferencing with police records showed that of the 57 injured impaired drivers involved in an MVC and brought to the ED, only 13 (22.8\%) were charged with impaired driving.

Comparisons between those charged and those not charged are shown in Table 2. Logistic regression between those charged and those not charged found only the median age and BAC to be significantly different. The median age was significantly higher for those charged with impaired driving (36 versus 28 years; $p=0.029)$. The median BAC was found to be significantly lower in those not charged (37 versus $47 \mathrm{mmol} / \mathrm{L} ; p=0.039$ ) with impaired driving.

Cross-referencing $10 \%$ of the medical records a second time by a research paramedic blinded to the study protocol found $100 \%$ concordance.

\section{DISCUSSION}

Impaired driving remains a far too common cause of preventable injuries and deaths. Our study found that $77 \%$ of injured impaired drivers were not subsequently charged with an impaired driving offense. This represents a missed opportunity to intervene and potentially prevent further mortality and morbidity. Although the first responsibility of the emergency physician is to manage the patient's injuries, a secondary goal is to initiate preventive treatment for alcohol abuse and dependence. Admission to a trauma centre creates a unique opportunity to identify and intervene in the cycle of alcohol abuse. Although the optimal intervention is still unknown, the most effective combination to reduce hazardous drinking and prevent recidivism appears to be alcohol counseling and treatment together with legal sanctions..$^{2-6}$ Unfortunately, our study is consistent with the growing body of North American literature suggesting that injured impaired drivers are escaping prosecution and thus likely to continue their dangerous behaviour. ${ }^{2,8-13}$

Now that this phenomenon has been uncovered in a number of Canadian jurisdictions, the question of why this occurs arises. Our study found that those not charged had a significantly lower median BAC; thus, it is possible that the police may have felt that those not charged were not intoxicated. The only other Canadian study to report BAC as a factor was the Calgary trauma registry review. ${ }^{13}$ This study did not find a significant difference in BAC between those convicted and those not convicted. Unfortunately, the Calgary study did not examine the relationship between BAC and impaired driving charges but rather only convictions.

The group not charged was also found to have a significantly younger median age than those not charged. This has not been previously reported, so further research is needed to look into age as a factor as to whether injured impaired drivers are charged. Our study did not suggest that the driver's injuries were a contributing factor as to whether a patient was charged. The two groups had similar measures of

\begin{tabular}{|lccc|}
\hline \multicolumn{4}{|l|}{ Table 2. Univariate comparisons of those who were and were not charged } \\
\hline Factor & Charged $(n=13)$ & Not charged $(n=44)$ & $p$ value \\
\hline Age $(y r)$ & 36 & 28 & $0.029^{*}$ \\
Male sex, $n(\%)$ & $11(85)$ & $38(86)$ & 0.873 \\
BAC (mmol/L) & 47 & 37 & $0.039^{*}$ \\
Single-vehicle status & $11(85)$ & $40(91)$ & 0.516 \\
Injury Severity Score & 13 & 12 & 0.458 \\
Glasgow Coma Scale score & 15 & 15 & 0.584 \\
\hline BAC $=$ blood alcohol concentration. & & & \\
${ }^{*} p<0.05$. & & & \\
\hline
\end{tabular}


injury as reflected in their initial GCS score and ISS. This is in contrast to the Calgary trauma registry study, which found that a lower severity of injury of the driver was associated with conviction. ${ }^{13}$ Part of this discrepancy may be explained by the fact that the patients in the Calgary study had more serious injuries, as reflected by a higher median ISS (22) compared to this study sample. It has also been suggested that injuries to others (nondriver) may play a role in persuading the police to charge an injured impaired driver. ${ }^{13}$ We examined this by determining whether the MVC was the result of a single-vehicle crash. Our results found that the majority were single-vehicle crashes; however, this was not a significant factor associated with legal charges. The Calgary study found that injuries to others (nondriver) were associated with convictions, as well as if there was a nondriver fatality (100\% conviction rate). Unfortunately, our study did not examine specific injuries to others but only if other vehicles were involved.

This study has several limitations. First, it was a retrospective review in which patients were selected based on their BAC. Although staff at the QEII HSC follow a policy to obtain BAC in every trauma team activation, it is possible that some patients did not have their BAC measured and hence would have been missed. Furthermore, inclusion in the study was also based on being able to identify the patient as the driver in an MVC. If this information was not available in the patient's records, then the patient was excluded from the study and further reduced the study population. As such, the final sample size for analysis was made up of only 57 patients. Previous studies on this phenomenon have also been limited by small sample sizes. ${ }^{8-11}$

\section{CONCLUSION}

In our study, $77 \%$ of injured alcohol-impaired drivers brought to the ED were not charged by police. This is a missed opportunity to change patients' behaviour to protect both themselves and society. Further research will need to determine what specific barriers exist in the ED to a police charge of impaired driving.

Acknowledgements: We would like to thank Agnieszka Grabowski-Comeau, Corinne Demone, Stacy Ackroyd, and Constable Scott MacDonald for their assistance during this study.
Competing interests: None declared.

\section{REFERENCES}

1. Mercer G. Estimating the presence of alcohol and drug impairment in traffic crashes and their costs to Canadians 1999 to 2006. Produced for MADD Canada by Applied Research and Evaluation Services (ARES), University of British Columbia. February 2009.

2. Purssell RA, Brown D, Brubacher J, et al. Proportion of injured drivers presenting to a tertiary care emergency department who engage in future impaired driving activities. Traffic Inj Prev 2010;11:35-42, doi:10.1080/15389580903419125.

3. Rauch WJ. Risk of alcohol-impaired driving recidivism among first offenders and multiple offenders. Am 7 Public Health 2010;100:919-24, doi:10.2105/AJPH.2008.154575.

4. McKnight AJ, Voas RB. The effect of license suspension upon DWI recidivism. Alcohol Drugs Driving 1991;7:43-54.

5. Kunitz S, Woodall $\mathrm{W}$, Zhao $\mathrm{H}$, et al. Re-arrest rates after incarceration for DWI: a comparative study in a southwestern US country. Am 7 Public Health 2002;92:1826-31, doi:10.2105/AJPH.92.11.1826.

6. Wells-Parker E, Bangert-Drowns R, McMillen R, et al. Final results from a meta-analysis of remedial interventions with drink/drive offenders. Addiction 1995;90:907-26, doi:10.1111/j.1360-0443.1995.tb03500.x.

7. Maull K, Kinning L, Hickman J. Culpability and accountability of hospitalized injured alcohol impaired drivers. $7 \mathrm{AMA}$ 1984;252:1880-3, doi:10.1001/jama.1984.03350140026019.

8. Biffl WL, Schiffman JD, Harrington DT, et al. Legal prosecution of alcohol-impaired drivers admitted to a level I trauma center in Rhode Island. 7 Trauma 2004;56:24-9, doi:10.1097/01.TA.0000108632.51898.DB.

9. Krause K, Howells G, Bair H, et al. Prosecution and conviction of the injured intoxicated driver. 7 Trauma 1998; 45:1069-72, doi:10.1097/00005373-199812000-00016.

10. Cydulka R, Harmody M, Barnoski A, et al. Injured intoxicated drivers: citation, conviction, referral and recidivism rates. Ann Emerg Med 1998;32:349-52, doi:10.1016/ S0196-0644(98)70012-5.

11. Lahn M, Gallagher J, Li S, et al. Prospective confirmation of low arrest rates among intoxicated drivers in motor vehicle crashes. Acad Emerg Med 2000;7:260-3, doi:10.1111/j.15532712.2000.tb01071.x.

12. Purssell RA, Yarema M, Wilson J, et al. Proportion of injured alcohol-impaired drivers subsequently convicted of an impaired driving criminal code offence in British Columbia. CFEM 2004;6:80-8.

13. Goecke M, Kirpatrick A, Laupland K, et al. Characteristics and conviction rates of injured alcohol impaired drivers admitted to a tertiary care Canadian trauma center. Clin Investig Med 2007;30:26-32.

14. Purssell RA. Emergency departments: are they considered a safe haven from prosecution for impaired drivers involved in fatal or personal injury crashes? BC Med 7 2010;52:477-9.

15. Chang S. The injured intoxicated driver: analysis of the conviction process. 7 Trauma 2001;51:551-6, doi:10.1097/ 00005373-200109000-00023. 